in low doses is an efficient adjunct. The higher dose of amphetamine produced either little or a great deal of responding. Perhaps, a higher dose of amphetamine would lead to a uniformly high response output.

In general, it appears that any high doses of a psychoactive drug used as an adjunct to RP is likely to produce an increment in persisting avoidance. The state produced by the high doses are likely to be aversive and the result is to produce sensitization of anxiety fear rather than desensitization (Amit \& Baum, 1970). All low doses of psychoactive agents, however, are not efficient adjuncts to RP. The fact that low doses of amphetamine are considerably more effective adjuncts to RP than fear-reducing agents suggests the necessity for fear expression before deconditioning can take place. The "relaxation" and distraction produced by most doses that have been tested as adjuncts to RP does not seem to hasten the deconditioning process. resistance-to-extinction of an avoidance response induced by certain drugs. Psychological Reports, 1970, 27, 310.

Baum, M. Extinction of avoidance responding through response prevention (flooding). Psychological Bulletin, 1970, 74, 276-284.

Cooper, S., Coon, K., Mejta, C., \& Reid, L. Methods of deconditioning persisting avoidance: Amphetamine, chlorpromazine and chlordiazepoxide as adjuncts to response prevention. Physiological Psychology, 1974, 2, 519-522.

Kamano, D. K. Using drugs to modify the effect of response prevention on avoidance extinction. Behavior Research and Therapy, 1972, 10, 367-370.

Kirk, R. E. Experimental design: Procedures for the behavioral sciences. Belmont, California: Brooks/Cole. 1968.

Voss, E. Mejta, C., \& Reid, L. Methods of deconditioning persisting avoidance: response prevention and counterconditioning after extensive training. Bulletin of the Psychonomic Society, $1974,3,345-347$.

\title{
REFERENCES
}

A mit, A., \& Baum, M. Comment on the increased

\section{Conditioned inhibition of the rabbit nictitating membrane response as a function of CS-UCS interval}

\author{
WILLIAM J. MAHONEY, SUZANNE E. KWATERSKI, and JOHN W. MOORE \\ University of Massachusetts, Amherst, Massachusetts
}

\begin{abstract}
Albino rabbits received differential conditioning in either a simple differential conditioning paradigm $(\mathrm{CS}+=$ light; $\mathrm{CS}-=$ tone) or a conditioned inhibition paradigm $(\mathrm{CS}+=$ light; $\mathrm{CS}-=$ light plus tone) at CS-UCS intervals (ISIs) of $.25, .5$, or $1.5 \mathrm{sec}$. Combined-cue summation tests and the results of subsequent conditioning to the tone (retardation tests) indicated that the tone acquired inhibitory properties at the longer ISIs but was "tuned out" at the shortest ISI resulting in a loss of salience.
\end{abstract}

The main purpose of this investigation was to assess the effect of CS-UCS interval on the strength of a Pavlovian conditioned inhibitor using summation and retardation tests of inhibition like those recommended by Rescorla (1969) and previously employed in our laboratory (e.g., Marchant, Mis, \& Moore, 1972; Marchant \& Moore, 1974). The specific hypothesis tested was that increasing a CS-UCS interval over that most efficient for simple conditioning would enhance the strength of the conditioned inhibitor, an expectation based on observations from both human and rabbit eye blink preparations that the CS-UCS interval optimal for differential conditioning is somewhat longer than that optimal for simple conditioning (Chisholm, Hupka, \& Moore, 1969; Hartman \& Grant, 1962; Vandercar \& Scheiderman, 1967).

This research was supported by National Science Foundation Grant GB 24557 to the third author. Requests for reprints should be sent to John W. Moore, Middlesex House, Department of Psychology, University of Massachusetts, Amherst, Massachusetts 01002 . The second author is now at Westfield State College, Westfield, Massachusetts.

\section{METHOD}

\section{Subjects and Apparatus}

The subjects were 48 naive albino rabbits. A detailed description of the apparatus is available elsewhere (e.g., Marchant, Mis, \& Moore, 1972). Briefly, four animals were run concurrently in individually ventilated and soundproofed file drawers while restrained in Plexiglas (Gormezano) boxes. A "minitorque" potentiomenter mounted on the rabbit's head was connected by a small metal hook and thread to a nylon loop sutured into the nictitating membrane (NM) of the right eye. Movement of the right NM produced a dc signal which was amplified and recorded on a Grass 5D oscillograph. A conditioned response (CR) was defined as a pen deflection of $1 \mathrm{~mm}$ (corresponding to an extension of the membrane of less than $1 \mathrm{~mm}$ ) occurring within the CS-UCS interval. The UCS was an ac shock of $2 \mathrm{~mA}$ and $50-\mathrm{msec}$ duration delivered through two stainless steel wound clip (Clay Adams, $9 \mathrm{~mm}$ ) electrodes attached to the skin of the intraorbital region of the right eye. Conditioned stimuli were as follows: (a) $\mathrm{CS}_{1}$ was the onset of two $4.5-\mathrm{V}$ incandescent lights mounted behind two translucent white plastic screens located on either side of the speaker directly in front of the animal; (b) $\mathrm{CS}_{2}$ was a burst of white noise at $80 \mathrm{~dB}$ (SPL); (c) $\mathrm{CS}_{3}$ was a tone of $1200 \mathrm{~Hz}$ at $85 \mathrm{~dB}$ delivered over a speaker located directly in front of the subject. On reinforced trials, the UCS overlapped the final $50 \mathrm{msec}$ of the CS. 


\section{Initial Conditioning}

All rabbits were habituated to the apparatus for a period of 30 min. Daily sessions of 100 trials each began the next day at an ISI of $.5 \mathrm{sec}$. The intertrial interval for all sessions was $30 \mathrm{sec}$. During the initial three daily sessions, the animals received 50 reinforced presentations each of $\mathrm{CS}_{1}$ and $\mathrm{CS}_{2}$. The order of stimulus presentation was unsystematically alternated. Rabbits responded to the light CS on $49.5 \%$ of trials on Day 3 and $95.4 \%$ on noise trials.

\section{Conditioned Inhibition Training}

The rabbits were divided into two groups, one receiving conditioned inhibition group training and the other receiving simple differential conditioning. Each group was divided into three subgroups $(\mathrm{N}=8)$ that differed in ISI, $.25, .75$ and $1.5 \mathrm{sec}$. The subjects in all subgroups were matched for percent CRs given on the last day of initial conditioning. Each group received 10 daily sessions of 100 trials. The conditioned inhibition groups received 50 reinforced trials of $\mathrm{CS}_{1}$ alone and 50 nonreinforced trials of the compound $\mathrm{CS}_{1}$ and $\mathrm{CS}_{3}$. The simple differential conditioning groups received 50 reinforced trials to $\mathrm{CS}_{1}$ alone and 50 nonreinforced trials to $\mathrm{CS}_{3}$ alone.

\section{Summation Testing}

On the day following the tenth day of conditioning inhibition training, all subjects were given 2 days of summation testing. Each day all subjects were presented with 50 nonreinforced trials of $\mathrm{CS}_{2}$ and 50 nonreinforced trials of the compound $\mathrm{CS}_{2}$ and $\mathrm{CS}_{3}$. The test stimulus was $.55 \mathrm{sec}$ in duration, and CRs were defined within this interval.

\section{Reacquisition}

Following summation testing, all rabbits were given two daily conditioning sessions consisting of 100 reinforced trials to $\mathrm{CS}_{3}$ alone at an ISI of $.5 \mathrm{sec}$.

\section{RESULTS}

\section{Differential Conditioning}

The left-hand portion of Figure 1 depicts the development of differential conditioning for each of the six principal groups. The most noteworthy aspect of first few training sessions was a suppression of conditioned responding in the .25- and 1.5- $\mathrm{sec}$ ISI groups compared with the last day of initial conditioning. This drop in conditioned responding in the case of the $.25-\mathrm{sec}$ ISI groups was probably due to truncation of the CR latency distribution. That is, CRs which would have normally occurred at intervals longer than $.25 \mathrm{sec}$ were excluded. The drop in conditioned responding at the $1.5-\mathrm{sec}$ ISI was probably due to the transition to an ISI unfavorable for efficient conditioning of the rabbit's NMR (Schneiderman \& Gormezano, 1964).

Differential conditioning performance was assessed by analyses of variance of (a) difference scores (\% CRs to $\mathrm{CS}+$ minus \% CRs to $\mathrm{CS}-$ ) averaged over the last four daily sessions and (b) ratio scores obtained by dividing the number of CRs to CS- by total CRs over the last four sessions. The only significant $(p<.001)$ sources of variability in the experimental design was the main effect contrast between the two paradigms of differential conditioning, conditioned inhibition training vs. simple differential conditioning, with $[\mathrm{F}(1,36)=$
28.19] for difference scores and $[F(1,36)=22.45]$ for ratio scores. Figure 1 indicates that the simple differential conditioning procedure resulted in the greater separation between responding to CS+ and CS-. The main effects of ISI and the interaction of ISI and training paradigm failed to approach statistical significance for either measure.

\section{Summation Test}

Figure 1 depicts the results of summation testing over two successive extinction sessions with CS duration a constant $.55 \mathrm{sec}$ for all groups. Noise and noise plus tone trials are plotted separately for each group. Inspection of Figure 1 indicates that the reduction of conditioned responding produced by combining the (presumably inhibitory) tone with the noise burst was greatest in the two .75-sec ISI groups, somewhat less pronounced in the $1.5 \mathrm{-sec}$ ISI groups, and essentially absent in the $.25 \mathrm{-sec}$ ISI groups, save for a slight (nonsignificant) reduction to noise plus tone relative to noise alone in the simple differential conditioning subgroup. Since the average CR rate on the first day of summation testing was at least $20 \%$, this relative absence of inhibitory summation in the .25 -sec ISI groups cannot be atrributed entirely to "floor" effects.

Analyses of variance of difference scores and ratio scores (number of CRs to noise plus tone divided by total CRs) averaged over the two test sessions indicated a significant $(p<.01)$ main effect of training ISI on each measure of inhibitory summation: $[\mathrm{F}(2,36)=8.74$ and $\mathrm{F}(2,36)=6.06]$ for difference and ratio scores, respectively. Individual $t$ test comparisons of ratio scores (deemed most suitable because of differences among groups in conditioned responding to noise alone) indicated that the .75- and 1.5-sec ISI groups with means of .264 and .277 , respectively, did not differ from each other while each differed from the .25 -sec ISI groups with a mean ratio score of .473 : $[\mathrm{t}(36)=3.14, \mathrm{p}<.01]$ for the .25 -sec ISI vs. the .75-sec ISI groups and [ $\mathrm{t}(36)=$ $2.93, \mathrm{p}<.01]$ for the $.25-\mathrm{sec}$ ISI vs. the $1.5-\mathrm{sec}$ ISI groups. No other sources of variance in the experimental design approached statistical significance for either measure of inhibitory summation.

\section{Retardation}

Figure 1 indicates that acquisition to the tone at an ISI of $.5 \mathrm{sec}$ was retarded on the first conditioning session following summation testing in the .25-sec ISI groups in comparison with the other groups. Analysis of variance of percentage of CRs on the first day of tone acquisition verified a significant main effect of training ISI $[F(2,36)=4.92, p<.05]$. No other sources of variance in the design approached significance $(\mathrm{Fs}<1)$.

\section{DISCUSSION}

The principal findings of this experiment were: (a) Conditioned inhibition training at ISIs longer than that 

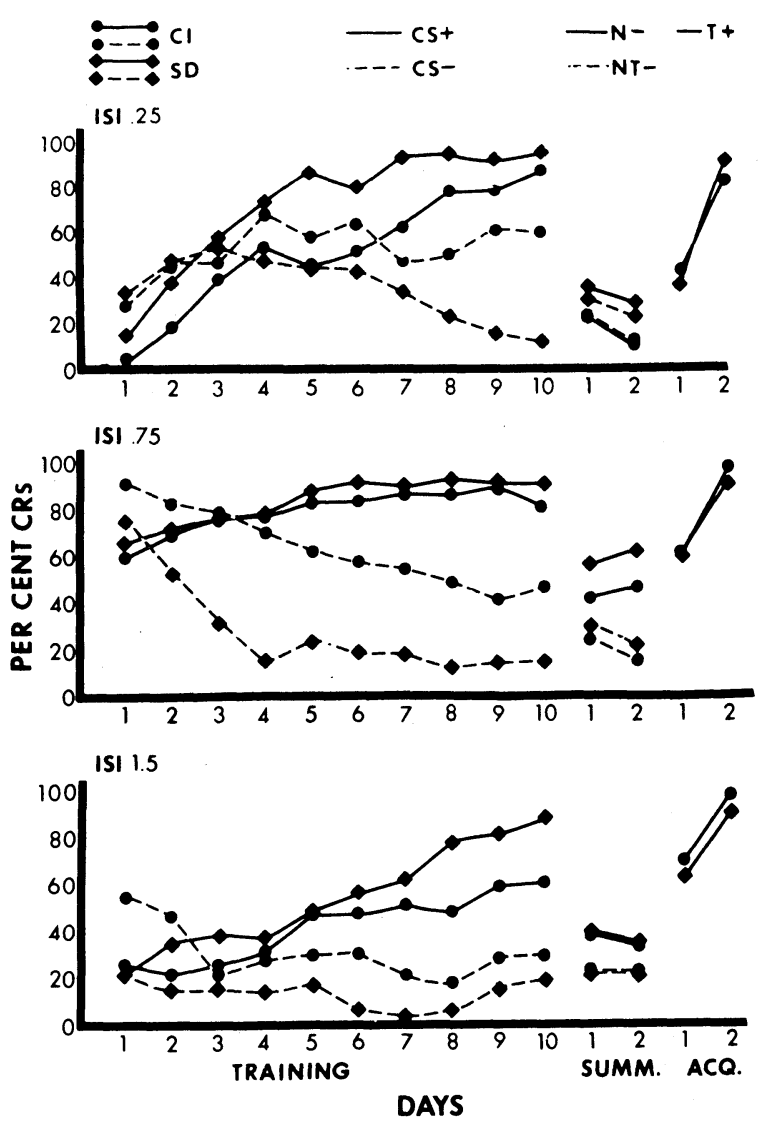

Figure 1. Differential conditioning, summation testing, and acquisition to the tone (T) as a function of ISI during differential conditioning and training paradigm. $\mathbf{C I}=$ conditioned inhibition; $\mathrm{SD}=$ simple differential conditioning, $\mathrm{N}=$ noise burst.

optimal for simple conditioning $(.75$ and $1.5 \mathrm{sec})$ resulted in greater inhibitory summation in a combined cue test than was obtained following training at an ISI of $.25 \mathrm{sec}$. (b) Groups which received differential conditioning at the $.25 \mathrm{sec}$ ISI were retarded in subsequent acquisition to the tone in comparision with groups trained at the longer ISIs. (c) There were no differences between the inhibitory potential of the tone, as assessed by summation and retardation testing, following simple differential conditioning in comparison with conditioned inhibition training.

The finding that conditioned inhibition training at ISIs longer than that optimal for simple conditioning was necessary in order to achieve an inhibitory summation effect in the combined cue test is generally consistent with the hypothesis offered by Hartman and Grant (1962) that the longer ISIs favor inhibitory processes while shorter ISIs favor excitation. The pattern of results in summation and retardation testing suggest why this may be the case. Specifically, the failure to obtain inhibitory summation in the .25 -sec ISI groups together with retarded acquisition to the tone in these groups in comparison with those trained at longer ISIs suggest that the tone lost salience through an habituation-like "tuning out" process during training with the .25-sec ISI. Such a "tuning out" of the tone would be consistent with the low level of responding to CS - under simple differential conditioning as well as the rather poor differential conditioning evident in the .25 -sec ISI conditioned inhibition group. The observation of retarded acquisition in the final phase of the experiment is consistent with a loss-of-salience interpretation, as is the failure to obtain inhibitory summation. The fact that the "tuning out" or loss of salience was robust with respect to the disinhibiting influence of the summation and retardation procedures (e.g., the switch from a tone duration of .30 to $.55 \mathrm{sec}$ between the training and testing phases) suggests that the "tuning out" process may not resemble reflex habituation, but rather involve poorly understood higher processes like those invoked to explain latent inhibition (cf. Lubow, 1973). With tones of longer duration, as in the two other ISI conditions, the tone appears to have developed active inhibitory properties, hence the summation effects apparent in Figure 1. At the very least, the tones in these groups did not appear to lose salience through systematic nonreinforcement.

It is therefore suggested that the advantage of longer ISIs in the development of differential conditioning lies in the resistance of a CS - of relatively long duration to loss of salience so that it may acquire active inhibitory properties. Whether there is any particular advantage in instilling active inhibitory properties by increasing the duration of $\mathrm{CS}$ - beyond a certain point remains an empirical question. In the present experiment, there did not appear to be any noteworthy differences between ISIs of .75 and $1.5 \mathrm{sec}$ in terms of summation testing (ratio scores) and retardation of acquisition to the tone.

Failure to observe differences in the inhibitory potential of the tone, assessed in terms of summation and retardation tests, in contrasting the two paradigms of differential conditioning raises questions regarding the validity of Wagner and Rescorla's (1972) theory of conditioned inhibition. According to their model, conditioned inhibition training should have resulted in greater inhibition to the tone than simple differential conditioning to a light as $\mathrm{CS}+$ and a tone alone as $\mathrm{CS}-$, because nonreinforcement of the tone occurred in the presence of an excitatory CS (light) in the former case, but alone in the latter. The difficulty here may lie in our use of white noise as the reference cue $\left(\mathrm{CS}_{2}\right)$ utilized in summation testing. As Figure 1 shows, conditioning to white noise in the initial, predifferential conditioning phase resulted in some generalized excitatory strength to the tone. Extinction of this generalized excitatory strength to the tone under both training procedures might have resulted in so much inhibition that our testing procedures were insensitive to any additional increments in inhibition resulting from nonreinforcement of the tone in the presence of the light.

\section{REFERENCES}

Chisholm, D. C., Hupka, R. B., \& Moore, J. W. Auditory differential conditioning of the rabbit nictitating membrane response: II. Effects of interstimulus interval and cue similarity. Psychonomic Science, 1969, 15, 125-126.

Hartman, T. F., \& Grant, D. A. Differential eyelid conditioning as a function of the CS-UCS interval. Journal of Experimental Psychology, 1962, 64, 131-136.

Lubow, R. E. Latent inhibition. Psychological Bulletin, 1973, 79, 398-407.

Marchant, H. G. III, Mis, F. W., \& Moore, J. W. Conditioned inhibition of the rabbit's nictitating membrane response. Journal of Experimental Psychology, 1972, 95, 408-411.

Marchant, H. G., III, \& Moore, J. W. Below-zero conditioned inhibition of the rabbit's nictitating membrane response. Journal of Experimental Psychology, 1974, 102, 350-352.

Rescorla, R. A. Pavlovian conditioned inhibition. Psychnlogical Bulletin, 1969, 72, 77-94.

Schneiderman, N., \& Gormezano, I. Conditioning of the nictitating membrane of the rabbit as a function of CS-US interval. Journal of Comparative and Physiological Psychology, 1964, 57, 188-195.

Vandercar, D. H., \& Schneiderman, N. Interstimulus interval functions in different response systems during classical discrimination conditioning of rabbits. Psychonomic Science, 1967, 9, 9-10.

Wagner, A. R., \& Rescorla, R. A. Inhibition in Pavlovian conditioning: Application of a theory. In Beakes, R. A., \& Halliday, M. S. (Eds.) Inhibition and learning. London: Academic Press, 1972.

(Received for publication October 21, 1974.) 